This item was submitted to Loughborough's Research Repository by the author.

Items in Figshare are protected by copyright, with all rights reserved, unless otherwise indicated.

\title{
Physical activity for primary dysmenorrhea: A systematic review and meta- analysis of randomized controlled trials
}

PLEASE CITE THE PUBLISHED VERSION

https://doi.org/10.1097/OGX.0000000000000618

\section{PUBLISHER}

Lippincott, Williams \& Wilkins

\section{VERSION}

AM (Accepted Manuscript)

\section{PUBLISHER STATEMENT}

This is a non-final version of an article published in final form in MATTHEWMAN, G. .... et al., 2018. Physical Activity for Primary Dysmenorrhea: A Systematic Review and Meta-analysis of Randomized Controlled Trials. Obstetrical and Gynecological Survey, 73(12), pp. 683 - 684.

\section{LICENCE}

CC BY-NC-ND 4.0

\section{REPOSITORY RECORD}

Matthewman, Gemma, Alexandra Lee, Jaidev G. Kaur, and Amanda Daley. 2019. "Physical Activity for Primary Dysmenorrhea: A Systematic Review and Meta-analysis of Randomized Controlled Trials". figshare. https://hdl.handle.net/2134/36673. 
Physical activity for primary dysmenorrhea: a systematic review and meta-analysis of randomized controlled trials

Authors

Dr Gemma MATTHEWMAN MSc Birmingham, West Midlands, UK; University of Birmingham

Dr Alexandra LEE MB ChB Birmingham, West Midlands, UK; University of Birmingham

Ms Jaidev G KAUR MPharm Birmingham, West Midlands, UK; University of Birmingham

Dr Amanda J DALEY PhD Birmingham, West Midlands, UK; University of Birmingham

Structured abstract word count: 333

Main text word count: 3182 
Corresponding author:

Dr Gemma Matthewman

Institute of Applied Health Research

University of Birmingham

Edgbaston

Birmingham

B15 2TT

gemmamatthewman@doctors.org.uk

The authors report no conflict of interest

Condensation: A systematic review and meta-analysis of randomized controlled trials of the effectiveness of physical activity as a treatment for primary dysmenorrhea

Short version of title: Physical activity for primary dysmenorrhea 
Structured Abstract

Background: Primary dysmenorrhea is cramping abdominal pain associated with menses. It is prevalent, affects quality of life, and can cause absenteeism. Although evidence based medical treatment options exist, women may not tolerate these or may prefer to use non-medical treatments. Physical activity has been recommended by clinicians for primary dysmenorrhea since the 1930s, but its effectiveness is still unknown.

Objective: We sought to determine the effectiveness of physical activity for the treatment of primary dysmenorrhea

Data sources: Systematic literature searches of multiple databases were performed, including searches for grey literature, from database inception to $24^{\text {th }}$ May 2017. Google searches and citation searching of previous reviews was also conducted.

Study eligibility criteria: Studies were selected using predefined selection criteria as specified in the registered protocol. Randomized controlled trials were included if they assessed physical activity interventions against any comparator over at least two menstrual cycles and assessed pain intensity or pain duration as an outcome. Study selection was performed by two independent reviewers at both the title/abstract and full text level.

Study appraisal and synthesis methods: Study quality was assessed by two independent reviewers using the Cochrane Risk of Bias Tool. Random effects metaanalyses for pain intensity and pain duration were conducted, with pre-specified subgroup analysis by type of physical activity intervention. 
Results: Searches identified 15 eligible randomized controlled trials; totalling 1681 participants. Data from 11 studies was included in the meta-analyses. Pooled results demonstrated significant effect estimates for physical activity versus comparators for pain intensity $(-1.89 \mathrm{~cm}$ on Visual Analogue Scale, 95\% confidence interval -2.96 to -1.09 ) and pain duration ( -3.92 hours, $95 \%$ confidence interval -4.86 , to -2.97$)$. Heterogeneity for both these results was high and only partly mitigated by subgroup analysis. Primary studies were of low or moderate methodological quality but results for pain intensity remained stable during sensitivity analysis by study quality.

Conclusion: Clinicians can inform women that physical activity may be an effective treatment for primary dysmenorrhea but there is a need for high quality trials before this can be confirmed.

Key words: Exercise, Menstrual Pain, Physical Activity, Primary Dysmenorrhea 
Main text

\section{Introduction}

Primary dysmenorrhea is pain occurring with menses in the absence of underlying pathology, commonly referred to as period pains or menstrual cramps by the lay press and public. ${ }^{1-4}$ Women may consider primary dysmenorrhea to be a normal physiological state rather than a disorder. ${ }^{5}$ However, studies consistently find it to be the most common gynaecological condition of adolescence, ${ }^{6-8}$ with severe symptoms reported by $13-33 \%^{9-11}$ of women and absenteeism by $24-43 \% .^{11-13}$

Approximately one third of women with primary dysmenorrhea have seen a health professional because of this condition. ${ }^{14,15}$

Standard, evidence based treatment is with non-steroidal anti-inflammatory medications (NSAIDs) ${ }^{16}$ or oral hormonal contraceptives. ${ }^{17}$ However, some women may not be able to use medications, or may prefer to avoid them. There are plausible mechanisms by which physical activity may reduce pain in primary dysmenorrhea. Pain during menstruation is thought to be mediated by uterine prostaglandins, which stimulate myometrial contractions. ${ }^{8}$ Pain sensitisation, ${ }^{8}$ psychosocial $^{18,19}$ and cultural factors $^{20}$ may also play a role. Physical activity reduces stress, ${ }^{21,22}$ has anti-nociceptive properties, ${ }^{23-26}$ reduces levels of PGF $2 \alpha^{27,28}$ (the prostaglandin subtype most closely linked with primary dysmenorrhea), ${ }^{8}$ and probably has hormonal effects on the menstrual cycle that are currently not fully understood. ${ }^{29}$

Physical activity has been recommended by clinicians for primary dysmenorrhea since the $1930 \mathrm{~s},{ }^{30,31}$ and this advice is reiterated on popular $^{1,3}$ and medical ${ }^{4,32}$ websites, including guidelines from the American College of Obstetrics and Gynaecology. ${ }^{33}$ However there is no clear evidence of effectiveness, ${ }^{34-36}$ and even less is known 
about which types of exercise might be beneficial or when these exercises should be performed. Three reviews of interventional studies of physical activity for primary dysmenorrhea have been performed (two narrative reviews in $1998^{36}$ and $2008^{34}$ and a systematic review in 2010). ${ }^{35}$ Results from these reviews were inconclusive due to lack of primary studies, and the searches for the most recent review were performed almost a decade ago in $2009 .{ }^{35}$ An unregistered systematic review was published in $2016^{37}$ but this appears to have a number of shortcomings such as low return rates on the initial searches for potentially eligible studies, an unclear meta-analysis with no measure of heterogeneity reported, and discrepancies in the methodological descriptions of studies in different sections of the report. An updated review is therefore required.

\section{Objective}

We sought to systematically review the evidence from randomized controlled trials (RCTs) of the use of physical activity as treatment for primary dysmenorrhea. We also proposed subgroup analyses based on type of intervention, type of comparator, and whether participants were adolescents or adults. ${ }^{38} \mathrm{We}$ planned to perform sensitivity analysis according to study quality (not specified in the registered protocol).

\section{Methods}

A protocol for this review was registered on PROSPERO on $7^{\text {th }}$ June 2017 prior to screening the studies (registration number 42017062202). ${ }^{38}$ The search strategy was developed building on search strategies from previous similar reviews ${ }^{18,22,23,34,35,39,40}$ by utilising common or unique but highly sensitive search terms. The following databases were used: Medline, Embase, Cochrane Database of Systematic Reviews, Cochrane Central Register of Controlled Trials, Science Citation Index, Social Sciences Citation Index, CINAHL, PsycINFO, SPORTDiscus, PEDro, AMED, Conference Proceedings 
Citation Index, Social Sciences Conference Proceedings Citation Index, WHO International Clinical Trials Registry Platform, Clinicaltrials.gov and OpenGrey. Google searches and citation searching of previous reviews were also conducted.

Indexing terms (where possible) and text words (title, abstract, key words and text search) were used for "physical activity" and "dysmenorrhea" terms. Language, date or publication type restrictions were not applied. "Humans" filters were used on some databases with large return rates (e.g. Medline) to enable easier handling of search results. Validated RCT filters were used where required, ${ }^{41-43}$ the inbuilt search filter was used for CINAHL. The Medline search strategy (see Appendix A) was piloted for sensitivity and specificity. Searches performed on other databases used the same text terms as the piloted Medline search, with index terms adapted for the specific database.

\section{Eligibility criteria}

Published and unpublished studies, in any language, were included where the following PICOS criteria were met:

- Participants: Non-athlete females with regular menstruation, experiencing primary dysmenorrhea, not using hormonal contraception

- Interventions: Physical activity interventions delivered over two or more menstrual cycles; as a single intervention or as a co-intervention, in any setting and via any mode of delivery

- Comparators: Any comparator that did not involve physical activity, including active comparators and usual care or no treatment

- Outcomes: Pain intensity measured by a validated tool or pain duration measured in hours 
- Study type: RCTs

Title and abstract screening was performed independently by two reviewers and any discrepancies were resolved by consensus between the two reviewers. In cases of uncertainty or when discrepancies could not be resolved the article was obtained as a full text. Where the full text could not be located the study authors were contacted where possible. Two theses and one conference abstract could not be located by any method and were thus excluded at the full text stage. Full text screening for inclusion of eligible studies was completed by two independent reviewers; discrepancies were resolved by consensus between these reviewers. Study authors were contacted for missing information with a reminder sent after three weeks if there had been no reply. In total, 20 study authors were contacted for further information regarding 17 studies but only five replied.

\section{Data extraction}

The data extraction form was adapted from the Cochrane Good Practice Data Extraction form ${ }^{44}$ and was piloted prior to use. Data from included studies was extracted for participants (setting, population, method of diagnosis, inclusion / exclusion criteria, sample size, age range), intervention (type of intervention, method, timing and frequency of delivery, duration), comparators (type of comparator, timing and duration), and outcomes (time point measured, measurement tool, mean, variance). Data extraction was completed by two independent reviewers using the full text copy and any supplementary information (protocols, correspondence from authors). The main publication was used as the reference and other sources were used to obtain any information that was not reported in the main study publication. Discrepancies were resolved by consensus between the two reviewers. 


\section{Assessment of risk of bias}

The Cochrane Collaboration Risk of Bias Tool was used ${ }^{45}$ with one adaption: "blinding of participants / personnel" was changed to "blinding to study purpose / group" as physical activity interventions do not allow complete blinding. ${ }^{34,46}$ Studies could therefore still be rated to be of high methodological quality despite being at high risk of bias. The main biases considered in the "other bias" section were recall bias, interviewer bias, contamination, the Hawthorne effect and the effect of cointerventions. Studies were assessed for quality at the study level by two independent reviewers using the Cochrane guidance. ${ }^{41}$ Discrepancies were resolved by consensus. Quality assessment was used for descriptive purposes and sensitivity analysis only.

\section{Data synthesis}

Review Manager 5.3 (Revman) was used for statistical analyses. Meta-analyses of pain intensity and duration were performed as specified in the review protocol. ${ }^{38}$ Where trials compared two exercise interventions against one comparator, they were considered as two separate trials; the number of participants in the comparator group was evenly divided between the trials to avoid double-counting of comparators. The variance was adjusted accordingly where required. The final participant number (n) was not provided for three studies; ${ }^{47-49}$ for these studies $\mathrm{n}$ was assumed to be the total randomized. Results for Ortiz $2015^{50}$ were obtained from a graph; they did not specify the measure of variance so this was assumed to be standard deviation.

Results were combined using the weighted mean difference, as most studies reported pain intensity using a visual analogue scale (VAS) in centimetres and pain duration in hours. VAS is a $10 \mathrm{~cm}$, usually horizontal, line anchored by the phrases "no pain" and "worst pain imaginable" at each end. One study" used the McGill questionnaire, 
which cannot be converted to VAS, so data from this trial could not be included in the meta-analysis. The remaining studies reported pain intensity using VAS in millimetres $^{50}$ and pain duration in days. ${ }^{49,52}$ These results were converted to centimetres and hours respectively before analysis. A correlation coefficient of 0.6 was used to estimate the standard deviation of the mean difference where this was not provided, based on the result obtained in an RCT of a physical activity intervention in a similar population. ${ }^{53}$ Inverse variance methods were used for weighting in the meta-analyses. The random effects model was used as it was anticipated there may be a high degree of heterogeneity. $I^{2}$ was used to assess heterogeneity; an $I^{2}$ value greater than $50 \%$ was considered to indicate substantial heterogeneity. ${ }^{41}$ Funnel plots were produced to look for publication bias.

Cluster RCTs could not be included in the meta-analyses as no intra-cluster correlation coefficient was reported in the eligible trials. Separate pooling of cluster RCTs was performed for pain duration but only one cluster randomized study reported pain intensity in a format that could be used. Subgroup analysis was not possible for comparator type as specified in the protocol due to insufficient primary studies. Subgroup analysis by age, which was also specified in the protocol, was not possible as most included studies did not provide enough detail on age ranges.

\section{Results}

Searches were performed on $24^{\text {th }}$ May 2017. The returns for individual databases are given in Appendix B. The PRISMA flow diagram, representing the flow of studies through the selection process, is shown in Figure 1. A list of studies excluded at the full text stage can be found in Appendix $\mathrm{C}$ with reasons for exclusion. Nine studies 
were only found in Persian or Mandarin. These papers were assessed with the assistance of native Persian and Mandarin speakers.

\section{Study characteristics}

Fifteen RCTs, all published since 2011, met the review inclusion and exclusion criteria. This resulted in a total of 1681 participants across all included studies. ${ }^{47-52,54-}$ ${ }^{66}$ Details of these studies are presented in Table 1. Included studies were small or medium sized single-centre trials from a range of countries but primarily Iran or India. Most studies recruited university students. Diagnosis of primary dysmenorrhea was usually based on clinical history, ${ }^{47-49,51,54-56,60-62,64-66}$ four studies performed a clinical examination for all participants,,$^{50,52,57,58}$ and three used ultrasound $d^{52,57,58}$ to exclude secondary causes. A range of physical activity interventions were used. These could be categorised into: aerobic exercise, ${ }^{48,50,54,56,60,62,66}$ stretching exercises, ${ }^{47,49-}$ $51,54,55,57,58,64,65$ yoga $^{48,52,59,61}$ or Kegels exercises. ${ }^{50,56,63,66}$ Ortiz 2015 used a mixed intervention. ${ }^{50}$ The majority of studies asked participants to perform exercises throughout the menstrual cycle, but not during menstruation. ${ }^{47,49,55,57,58,60,64}$ Reyhani 2013 asked participants to exercise by brisk walking for the first three days of menstruation. ${ }^{62}$ Rakhshaee 2011 asked participants to perform yoga in the luteal phase of the menstrual cycle. ${ }^{61}$

\section{Synthesis of results}

Meta-analysis of pain intensity (Figure 3) produced a pooled effect estimate of $-1.89 \mathrm{~cm}(95 \% \mathrm{CI}-2.96$ to -1.09$)$, representing a statistically significant reduction in pain intensity for those in the intervention (physical activity) group relative to comparators. Heterogeneity was high $\left(I^{2}=95 \%\right)$. 
Subgroup analysis by intervention demonstrated effect sizes of $-1.29 \mathrm{~cm}(95 \% \mathrm{CI}-2.38$ to $\left.-0.21, I^{2} 83 \%\right)$ for aerobic exercise interventions; $-1.67 \mathrm{~cm}(95 \% \mathrm{CI}-2.70$ to -0.63 , $\left.I^{2} 94 \%\right)$ for stretching exercise interventions; $-1.81 \mathrm{~cm}\left(95 \% \mathrm{CI}-2.37\right.$ to $\left.-1.61, I^{2} 0 \%\right)$ for yoga interventions; $-1.68 \mathrm{~cm}\left(95 \%\right.$ CI -2.43 to $\left.-0.93, I^{2} 0 \%\right)$ for Kegels exercise interventions and $-4.70 \mathrm{~cm}(95 \% \mathrm{CI}-5.15$ to -4.25$)$ for the single mixed intervention trial. Studies that could not be included in the meta-analysis demonstrated the same direction of treatment effect. ${ }^{51,58,60,61,65}$

Meta-analysis of pain duration (Figure 4) produced a pooled estimate of effect of -3.92 hours $(95 \% \mathrm{CI}-4.86$ to -2.97$)$, representing a reduction in pain duration for those in the intervention (physical activity) group relative to comparators. Heterogeneity was high $\left(I^{2}=78 \%\right)$. Data from two cluster RCTs was combined with a similar pooled effect size of -3.34 hours $(95 \%$ CI -4.15 to -2.53$)$.

Subgroup analysis by intervention demonstrated effect sizes of -15.64 hours $(95 \%$ CI -26.96 to $\left.-4.32, I^{2} 49 \%\right)$ for aerobic exercise interventions; -3.53 hours $(95 \%$ CI -4.25 to $\left.-2.81, I^{2} 82 \%\right)$ for stretching exercise interventions; -6.74 hours $(95 \%$ CI -13.4 to $\left.-0.03, I^{2} 32 \%\right)$ for yoga exercise interventions; and -21.00 hours $(95 \%$ CI -38.70 to -3.30 ) for the single Kegels exercise intervention.

Sensitivity analysis was performed for type of comparator and timing of intervention, with no significant change in the combined estimate of treatment effect. Funnel plot asymmetry was seen for both outcomes. Pain intensity did not demonstrate the classical funnel shape, possibly due to the heterogeneity of primary studies. The funnel plot for pain duration suggested publication bias. This is potentially due to selective outcome reporting as five studies included in the pain intensity meta-analysis did not publish data on pain duration, and most studies were found to be at a high 
risk of selective outcome reporting. However, results remained statistically significant when the smaller studies contributing to this asymmetry were removed.

Analysis of absenteeism was planned but this was only reported in one study with no measure of variance given. ${ }^{49}$

\section{Risk of bias of included studies}

Most included studies were at high risk of bias in multiple areas of study design, or did not report sufficiently in order for a conclusion to be made about the risk of bias (see Figure 2). The randomization process was not fully described for most studies ${ }^{47-}$ $49,51,55,56,58,60,61,64-66$ and allocation concealment was only performed in two studies. ${ }^{50,59}$ No studies reported blinding participants to study purpose or group and only one study reported blinding outcome assessors. ${ }^{50}$ Registered protocols were found for three studies, ${ }^{49,51,56,64-66}$ of which two proposed outcomes that were not reported in the final study. ${ }^{64,65}$ Selective outcome reporting is also suggested by the range of outcomes reported across studies. Results were sometimes reported incompletely; ${ }^{50,51,55,65}$ for example, Aboushady $2016^{55}$ did not report post-intervention pain intensity in the control group. Most studies had no loss to follow up, ${ }^{49,51,52,55,56,58,59,62-66}$ the remaining studies did not use intention to treat analysis ${ }^{50,57,61}$ or are unclear. ${ }^{47,48,60}$

Most biases would be expected to affect the results such that they increased the magnitude of the treatment effect. However, when low quality studies were removed (Score $<3$ on risk of bias assessment in Figure 2), there was an increase in the pooled estimate of treatment effect for pain intensity (from $-1.89 \mathrm{~cm}(95 \%$ CI -2.96 to -1.09$)$ to $-2.87 \mathrm{~cm}(95 \% \mathrm{CI}-5.10$ to -0.63$))$. Only one study of moderate quality assessed pain duration with a non-significant estimate of treatment effect of -2.64 
hours $(95 \%$ CI -11.58 to 6.30$)$ suggesting that the evidence for the effect of physical activity on pain duration is less reliable.

\section{Comment}

\section{Main findings}

This systematic review and meta-analysis suggests that physical activity may be an effective intervention for primary dysmenorrhea. However, these results should be interpreted with caution, as heterogeneity was high and only partially mitigated by sub group analysis. Studies were of low or moderate quality, mainly due to performance bias and potential selective outcome reporting. Nevertheless, results for pain intensity remained stable when low quality studies were removed providing some reassurance of the treatment effect observed. All studies demonstrated an improvement in pain (intensity and / or duration) with intervention, including those that could not be included in the meta-analysis.

\section{Strengths and limitations}

Unlike previous reviews, this review was completed in conjunction with current guidelines for conducting and reporting systematic reviews. ${ }^{41,67}$ A prospective protocol was registered on PROSPERO, ensuring methods were specified a priori. ${ }^{38}$ Substantially more RCTs were found in this review than all previous reviews, mostly due to expansion in the primary literature. Searches used in this review were also more comprehensive than previous reviews; covering more databases, and identifying grey literature, such as theses and conference proceedings that were not identified in previous reviews. All eligible studies that were not published in English were translated so that they could be considered for inclusion. In compliance with current 
best practice guidelines for systematic reviews, eligibility screening, data extraction and quality assessment were all performed by two independent reviewers. The metaanalyses for this review contain the largest number of RCTs to date, and assess both pain intensity and pain duration (only the former has been previously assessed by meta-analysis). Our review is also the first to include subgroup analysis by type of physical activity. Interrogation of the data using sensitivity analysis and Funnel plots was performed, which was not the case in previous reviews. This review is therefore the most complete, up to date and methodologically rigorous review of the effectiveness of physical activity interventions for primary dysmenorrhea.

Despite this the findings remain limited by the number of primary studies, trial sample size and the quality of included studies. No high quality trials were identified, and reporting of trial methodology was not always clear. The results of this review are subject to high levels of heterogeneity, introducing some uncertainty about the effectiveness of physical activity. Heterogeneity appeared to occur because studies evaluated a wide range of physical activity interventions. Attempts to resolve this by conducting subgroup analysis were somewhat limited because of insufficient primary studies. Insufficient data from primary studies also prevented reporting of one of the pre-specified outcomes (absenteeism) and two of the pre-specified subgroup analyses (adolescents and adults, comparator type).

\section{Comparison with existing literature}

Previous literature regarding the use of physical activity for primary dysmenorrhea is predominantly limited by insufficient primary studies. Consistent with our findings, increased physical activity was identified as a small protective factor against experiencing dysmenorrhea in a 2006 systematic review of observational studies (odds 
ratio (OR) of $0.89,95 \% \mathrm{CI} 0.80$ to 0.99$).{ }^{18} \mathrm{~A}$ non-systematic review of controlled trials published in 1998 also found a beneficial effect, but noted there was a paucity of methodologically robust studies to confirm this. ${ }^{36}$ Interestingly, it considered three trials to be randomized despite not being reported as such, and not being considered as such in other reviews. ${ }^{34,35}$ Interventional studies were reviewed again in 2009 in a non-systematic review ${ }^{34}$ and in 2010 as a Cochrane Library systematic review, ${ }^{35}$ which included both primary and secondary dysmenorrhea in the same review. Both reviews identified just one small RCT which demonstrated a beneficial effect of treadmill running. ${ }^{68}$ This trial had some methodological flaws and therefore the study authors concluded that there was insufficient evidence to recommend the intervention. The results of the current systematic review and meta-analyses are also consistent with those found in a systematic review published in 2016, which had potential methodological limitations mentioned previously. ${ }^{37}$

As well as considering the statistical significance and methodological quality of the results it is important to place these within a clinical context. No minimal clinically important difference (MCID) is available in the literature for pain intensity measured by VAS in primary dysmenorrhea, but the MCID in endometriosis is $1 \mathrm{~cm} .{ }^{69}$ This suggests that the pooled estimate, at almost $2 \mathrm{~cm}$, is clinically significant. There are no reported values for the MCID for pain duration in primary dysmenorrhea or similar conditions.

\section{Conclusions and Implications}

This review provides evidence that physical activity may reduce pain intensity and duration in primary dysmenorrhea. However, although physical activity is currently recommended in clinical guidelines for primary dysmenorrhea, more high quality 
studies are needed before this can be confirmed. Potential future trials should adhere to international reporting guidelines as well as attempting to minimise sources of bias. Trials that evaluate optimum type of physical activity intervention and timing for physical activity within the menstrual cycle are also required. 
Acknowledgements:

Sue Bayliss (University of Birmingham) for assistance with building the search strategy, Sayeed Haque (University of Birmingham) for assistance with statistical analysis), Natalie-Tyldesley-Marshall (University of Birmingham) for assistance with reviewing articles, Manadana Zanganeh (University of Birmingham) for assistance with translating and reviewing articles published in Persian, Zhaonan Wang (University of Birmingham) for assistance with translating and reviewing articles published in Mandarin. 
References

1. Uzoma K. Can exercising stop menstrual cramps? 2015;

http://www.livestrong.com/article/384938-can-exercising-stop-menstrual-cramps/.

Accessed 10th April, 2017.

2. Wilkinson E. Exercise 'no aid' for period pain. 2009;

http://www.nhs.uk/news/2009/12December/Pages/Exercise-no-relief-for-period-pain.aspx.

Accessed 10th April, 2017.

3. 5-Minute Workout: Relief from Cramps. 2017;

http://www.fitnessmagazine.com/workout/express/5-minute/moves-to-relieve-cramps/.

Accessed 10th April, 2017.

4. $\quad$ NHS Choices. Period Pain. 2016; http://www.nhs.uk/conditions/periodspainful/pages/introduction.aspx\#Treating. Accessed 10th April, 2017.

5. Wong LP. Attitudes towards dysmenorrhoea, impact and treatment seeking among adolescent girls: a rural school-based survey. Australian Journal of Rural Health. 2010;19:218 - 223.

6. Berkley KJ. Primary dysmenorrhea: An urgent mandate. Pain: Clinical Updates. 2013;21(3).

7. Proctor M, Farquhar C. Diagnosis and management of dysmenorrhoea. BMJ. 2006;332(7550):1134 - 1138.

8. lacovides S, Avidon I, Baker FC. What we know about primary dysmenorrhea today: a critical review. Human Reproduction Update. 2015;21(6):762 - 778.

9. Suvitie PA, Hallamaa MK, Matomaki JM, Makinen JI, Perheentupa AH. Prevalence of Pain Symptoms Suggestive of Endometriosis Among Finnish Adolescent Girls (TEENMAPS Study). Journal of Pediatric and Adolescent Gynecology. 2016;29(2):97 103.

10. Nooh AM, Abdul-Hady A, El-Attar N. Nature and prevalence of menstrual disorders among teenage female students at Zagazig University, Zagazig, Egypt. Journal of Pediatric and Adolescent Gynecology. 2016;29(2):137 - 142.

11. Esen I, Oğuz B, Serin HM. Menstrual characteristics of pubertal girls: A questionnairebased study in Turkey. Journal of Clinical Research in Pediatric Endocrinology. 2016;8(2):192 - 196.

12. Banikarim C, Chacko MR, Kelder SH. Prevalence and impact of dysmenorrhea on Hispanic female adolescents. Archives of Pediatric and Adolscent Medicine. 2000;154:1226.

13. Agarwal A, Venkat A. Questionnaire study on menstrual disorders in adolescent girls in Singapore. Journal of Pediatric and Adolescent Gynecology. 2009;22:365.

14. Hewison A, Van den Akker OB. Dysmenorrhoea, menstrual attitude and GP consultation. British Journal of Nursing. 1996;5(8):480 - 484.

15. Hillena TIJ, Grbavac SL, Johnston PJ, Straton JAY, Keogh JMF. Primary dysmenorrhea in young Western Australian women: prevalence, impact, and knowledge of treatment. Journal of Adolescent Health. 1999;25(1):40 - 45.

16. Majoribanks J, Ayeleke RO, Farquar C, Proctor M. Nonsteroidal anti-inflammatory drugs for dysmenorrhoea. Cochrane Database of Systematic Reviews. 2015:CD001751.

17. Wong $\mathrm{CL}$, Farquhar $\mathrm{C}$, Roberts $\mathrm{H}$, Proctor M. Oral contraceptive pill for primary dysmenorrhoea. Cochrane Database of Systematic Reviews. 2009(4):CD002120.

18. Latthe P, Mignini L, Gray R, Hills R, Khan K. Factors predisposing women to chronic pelvic pain: systematic review. BMJ. 2006;332:749 - 755.

19. Ju H, Jones $\mathrm{M}$, Mishra $\mathrm{G}$. The prevalence and risk factors of dysmenorrhea.

Epidemiologic Review. 2014;36:104 - 113. 
20. Faramarzi M, Salmalia H. Association of Psychologic and Nonpsychologic Factors With Primary Dysmenorrhea. Iranian Red Crescent Medical Journal. 2014; 16(8).

21. Josefsson $T$, Lindwall $M$, Archer $T$. Physical exercise intervention in depressive disorders: meta-analysis and systematic review. Scandinavian Journal of Medicine and Science in Sports. 2014;24(2):259 - 272.

22. Byrne A, Byrne DG. The effect of exercise on depression, anxiety and other mood states: a review. Journal of Psychosomatic Research. 1993;37(6):565 - 574.

23. Geneen L, Moore RA, Clarke C, Martin D, Colvin LA, Smith BH. Physical activity and exercise for chronic pain in adults: an overview of Cochrane Reviews. Cochrane Database of Systematic Reviews. 2017:CD011279.

24. Stagg NJ, Mata HP, Ibrahim MM, et al. Regular exercise reverses sensory hypersensitivity in a rat neuropathic pain model: role of endogenous opioids. Anaesthesiology. 2011;114(4):940 - 948.

25. Bortz WM, Angwin P, Mefford IN. Catecholamines, dopamine and endorphin levels during extreme exercise. New England Journal of Medicine. 1981;305:466 - 467.

26. Colt EW, Wardlaw SL, Frantz AG. The effect of running on plasma beta endorphin. Life Sciences. 1981;28:1637 - 1640.

27. Anderson SD, Pojer R, Smith ID, Temple D. Exercise-related changes in plasma levels of 15-keto-13,14-dihydro-prostaglandin F2alpha and noradrenaline in asthmatic and normal subjects. Scand J Respir Dis. 1976;57(1):41 - 48.

28. Rong Z, Shan F. The efficacy and mechanism of yoga treatment for primary dysmenorrhea suffered by female college students. Journal of Physical Education Guangzhou. 2013;20(6):115 - 119.

29. Stoddard JL, Dent CW, Shames L, Bernstein L. Exercise training effects on premenstrual distress and ovarian steroid hormones. European Journal of Applied Physiology. 2006;99:27 - 37.

30. Clow AES. Treatment of dysmenorrhoea by exercise. BMJ. 1932;1:4 - 5.

31. Any Questions? Exercises for dysmenorrhoea. BMJ. 1960;1:71.

32. Smith RP, Kaunitz AM. Patient education: Painful menstrual periods (dysmenorrhea). Beyond the Basics 2017; https://www.uptodate.com/contents/painful-menstrual-periodsdysmenorrhea-beyond-the-basics. Accessed 10th April, 2017.

33. American College of Obstetrics and Gynaecology. Dysmenorrhea: Painful Periods. 2015; https://www.acog.org/Patients/FAQs/Dysmenorrhea-Painful-Periods. Accessed 22nd November, 2017.

34. Daley AJ. Exercise and primary dysmenorrhoea : a comprehensive and critical review of the literature. Sports Medicine. 2008;38(8):659 - 670.

35. Brown J, Brown S. Exercise for dysmenorrhoea. Cochrane Database of Systematic Reviews. 2010(2):CD004142.

36. Golomb LM, Solidum AA, Warren MP. Primary dysmenorrhea and physical activity. Medicine and Science in Sports and Exercise. 1998;30(6):906 - 909.

37. Abaraogu UO, Tabansi-Ochiogu CS, Igwe ES. Effectiveness of exercise therapy on pain and quality of life of patients with primary dysmenorrhea: a systematic review with meta-analysis. Turkish Journal of Physical Medicine and Rehabilitation. 2016;62(4):346 354.

38. Matthewman G, Daley AJ, Bates E. A systematic review of randomised controlled trials of the effectiveness of increased physical activity as a treatment option in primary dysmenorrhoea. PROSPERO. 2017:CRD42017062202.

39. Mishra SI, Scherer RW, Snyder C, Geigle PM, Berlanstein DR, Topaloglu O. Exercise interventions on health-related quality of life for people with cancer during active treatment. Cochrane Database of Systematic Reviews. 2012:CD008465. 
40. Proctor D, Murphy PA, Pattison HM, Suckling JA, Farquhar C. Behavioural interventions for dysmenorrhoea. Cochrane Database of Systematic Reviews. 2007:CD002248.

41. Higgins JPT, Green S. Cochrane Handbook for Systematic Reviews of Interventions. In: Higgins JPT, Green S, eds.: The Cochrane Collaboration; 2011.

42. Wong SS-L, Wilczynski NL, Haynes RB. Developing optimal search strategies for detecting clinically sound treatment studies in EMBASE. Journal of the Medical Library Association. 2006;94(1):41 - 47.

43. Eady AM, Wilczynski NL, Haynes RB. PsyclNFO search strategies identified methodologically sound therapy studies and review articles for use by clinicians and researchers. Journal of Clinical Epidemiology. 2008;61(1):34 - 40.

44. Effective Practice and Organisation of Care (EPOC) Group. Data extraction form. EPOC Rescources for Review Authors. 2013.

45. Hartling L, Ospina $M$, Liang $Y$, et al. Risk of bias versus quality assessment of randomised controlled trials: cross sectional study. BMJ. 2009;339:1017.

46. Theou $\mathrm{O}$, Stathokostas $\mathrm{L}$, Roland KP, et al. The effectiveness of exercise interventions for the management of frailty: A systematic review. Journal of Aging Research. 2011;569194.

47. Patel NS, Tanna T, Bhatt S. Effect of active stretching exercises on primary dysmenorrhea in college going female students. Indian Journal of Physiotherapy and Occupational Therapy. 2015;9(3):72 - 76.

48. Siahpour T, Nikbakht M, Rahimi E, Rabiee MA. The effect of 8 weeks aerobic exercise and yoga on primary dismenorrhea. Armaghane-Danesh, Yasuj University of Medical Sciences Journal 2013:483.

49. Motahari-Tabari N, Shirvani MA, Alipour A. Comparison of the effect of stretching exercises and mefenamic acid on the reduction of pain and menstruation characteristics in primary dysmenorrhea: A randomized clinical trial. Oman medical journal. 2017;32(1):47 - 53.

50. Ortiz MI, Cortes-Marquez SK, Romero-Quezada LC, Murguia-Canovas G, Jaramillo-Diaz AP. Effect of a physiotherapy program in women with primary dysmenorrhea.

European Journal of Obstetrics Gynecology and Reproductive Biology. 2015;194:24 - 29.

51. Behbahani BM, Ansaripour L, Akbarzadeh M, Zare N, Hadianfard MJ. Comparison of the effects of acupressure and self-care behaviors training on the intensity of primary dysmenorrhea based on McGill pain questionnaire among Shiraz University students. Journal of Research in Medical Sciences. 2016;21:104.

52. Yang NY, Kim SD. Effects of a yoga program on menstrual cramps and menstrual distress in undergraduate students with primary dysmenorrhea: A single-blind, randomized controlled trial. Journal of Alternative and Complementary Medicine. 2016;22(9):732 - 738.

53. Ussher $\mathrm{M}$, Lewis $\mathrm{S}$, Aveyard $\mathrm{P}$, et al. Physical activity for smoking cessation in pregnancy: Randomised controlled trial. BMJ. 2015:350.

54. Vaziri F, Hoseini A, Kamali F, Abdali K, Hadianfard M, Sayadi M. Comparing the effects of aerobic and stretching exercises on the intensity of primary dysmenorrhea in the students of universities of Bushehr. Journal of Family and Reproductive Health. 2015;9(1):23 - 28.

55. Aboushady RM-N, El-Saidy TMK. Effect of home based stretching exercises and menstrual care on primary dysmenorrhea and premenstrual symptoms among adolescent girls. IOSR Journal of Nursing and Health Science. 2016;5(2):10 - 17.

56. Nasri M, Barati AH, Ramezani AR. Comparison of aerobic training and pelvic floor muscle exercise on primary dysmenorrhea in adolescent girls. Journal of Clinical Nursing and Midwifery. 2016;5(3):53 - 61. 
57. Saleh HS, Mowafy HE, Abd El Hameid AA. Stretching or core strengthening exercises for managing primary dysmenorrhea. Journal of Womens Health Care. 2016;5(1):1 - 6.

58. Shahr-Jerdy S, Hosseini RS, Eivazi M. Effects of stretching exercises on primary dysmenorrhea in adolescent girls. Biomedical Human Kinetics. 2012;4:127 - 132.

59. Yonglitthipagon $P$, Muansiangsai $S$, Wongkhumngern $W$, et al. Effect of yoga on the menstrual pain, physical fitness, and quality of life of young women with primary dysmenorrhea. Journal of Bodywork and Movement Therapies. 2017. http://onlinelibrary.wiley.com/o/cochrane/clcentral/articles/619/CN-01308619/frame.html.

60. Sutar A, Paldhikar S, Shikalgar N, Ghodey S. Effect of aerobic exercises on primary dysmenorrhoea in college students. IOSR Journal of Nursing and Health Science. 2016;5(5):20 - 24.

61. Rakhshaee Z. Effect of three yoga poses (cobra, cat and fish poses) in women with primary dysmenorrhea: a randomized clinical trial. Journal of Pediatric and Adolescent Gynecology. 2011;24(4):192 - 196.

62. Reyhani T, Jafarnejad F, Behnam $H$, Ajam M, Baghaei M. The effect of brisk walking on primary dysmenorrhea in girl students. Iranian Journal of Obstetrics, Gynecology and Infertility. 2013;16(46):14 - 19.

63. Kaur A, Gaurav S, Dhakshinamoorty P. Comparison of effect of fast and slow kegels exercises in reducing pain in primary dysmenorrhoea: experimental design.

Physiotherapy and Occupational Therapy Journal. 2013;6(135 - 41).

64. IRCT201203118822N2. Comparative effectiveness of mefenamic acid capsules, ginger and stretching exercise on primary dysmenorrhea. In:2013.

65. IRCT2013071013940N1. Effect of accupressure on primary dysmenorrhea. In. Shiraz University of Medical S, trans2014.

66. IRCT2014042017362N1. The effects of two selected types of training on primary dysmenorrhea in adolescent girls. In:2014.

67. Moher D, Liberati A, Tetzlaff J, Altman DG, The PRISMA Group. Preferred reporting items for systematic reviews and meta-analyses: The PRISMA statement. Annals of Internal Medicine. 2009;151(4).

68. Israel RG, Sutton M, O'Brien KF. Effects of aerobic training on primary dysmenorrhea symptomatology in college females. Journal of American college Health. 1985;33:241 244.

69. Gerlinger C, Schumacher U, Faustman T, Colligs A, Schmitz H, Seitz C. Defining a minimal clinically important difference for endometriosis-associated pelvic pain measured on a visual analog scale: analyses of two placebo-controlled, randomized trials. Health and Quality of Life Outcomes. 2010;8:138. 
Table 1 - Description of included studies

"Cycles" refers to menstrual cycles

\begin{tabular}{|c|c|c|c|c|c|c|}
\hline Study & $n$ & Participants & Intervention(s) & Comparator(s) & Outcome(s) & Results \\
\hline $\begin{array}{l}\text { Aboushady } \\
2016^{55}\end{array}$ & $\begin{array}{l}8 \\
0\end{array}$ & $\begin{array}{l}\text { School / college } \\
\text { students, Saudi } \\
\text { Arabia }(16-21 \mathrm{yrs})\end{array}$ & $\begin{array}{l}\text { Instructional sessions (Menstrual } \\
\text { care, stretches); exercises at home, } \\
\text { 20-30mins, 2x/day, 3d/w for } 8 \mathrm{wks}\end{array}$ & $\begin{array}{l}\text { Menstrual care } \\
\text { instructional } \\
\text { session only }\end{array}$ & $\begin{array}{l}\text { Pain duration } \\
\text { Pain intensity } \\
\text { via VAS }\end{array}$ & $\begin{array}{l}\text { Statistically significant difference in } \\
\text { pain duration } \\
\text { Pain intensity only reported as } \\
\text { pre/post-test }\end{array}$ \\
\hline $\begin{array}{l}\text { Behbahani } \\
2016^{51,65}\end{array}$ & $\begin{array}{l}1 \\
2 \\
0\end{array}$ & $\begin{array}{l}\text { Non-medical } \\
\text { students, Iran }(18- \\
25 \mathrm{yrs})\end{array}$ & $\begin{array}{l}\text { - 4wks educational classes } \\
\text { (physiology, nutrition, exercises), } \\
\text { "isometric exercises" at home for } \\
\text { 4wks }\end{array}$ & $\begin{array}{l}\text { Acupressure } \\
\text { during pain } \\
\text { Ibuprofen } 400 \mathrm{mg} \\
3 x / \text { day }\end{array}$ & $\begin{array}{l}\text { Pain intensity } \\
\text { via McGill } \\
\text { questionnaire }\end{array}$ & $\begin{array}{l}\text { Statistically significant reduction in } \\
\text { pain intensity in exercise / } \\
\text { acupressure groups compared to } \\
\text { ibuprofen }\end{array}$ \\
\hline $\begin{array}{l}\text { Kaur } \\
2013 a\end{array}$ & $\begin{array}{l}2 \\
4\end{array}$ & $\begin{array}{l}\text { Hostel at Post- } \\
\text { Graduate Institute, } \\
\text { India (19-25yrs) }\end{array}$ & $\begin{array}{l}\text { Slow Kegels group: } \\
\text { - Hot pack, 90x Kegel exercises alt } \\
\text { days, 5-10s hold; for 8wks } \\
\text { Fast Kegels group as above, no hold }\end{array}$ & $\begin{array}{l}\text { Hot pack over } \\
\text { lower abdomen } \\
\text { for } 10 \mathrm{mins}\end{array}$ & $\begin{array}{l}\text { Pain intensity } \\
\text { via VAS }\end{array}$ & $\begin{array}{l}\text { No statistically significant difference } \\
\text { in pain intensity between slow } \\
\text { Kegels and control } \\
\text { Statistically significant reduction in } \\
\text { pain intensity in fast Kegels } \\
\text { compared to control }\end{array}$ \\
\hline $\begin{array}{l}\text { Motahari- } \\
\text { Tabari } \\
2017^{49,64}\end{array}$ & $\begin{array}{l}1 \\
2 \\
2\end{array}$ & $\begin{array}{l}\text { Medical students, } \\
\text { Iran (Age range not } \\
\text { reported) }\end{array}$ & $\begin{array}{l}\text { - } 15 \text { mins abdominal / pelvic } \\
\text { stretching exercises, taught } \\
\text { initially, } 3 \mathrm{x} / \mathrm{wk} \text {; for } 2 \text { cycles }\end{array}$ & $\begin{array}{l}\text { Mefenamic acid } \\
250 \mathrm{mg} 3 \mathrm{x} / \text { day }\end{array}$ & $\begin{array}{l}\text { Pain intensity } \\
\text { via VAS } \\
\text { Pain duration }\end{array}$ & $\begin{array}{l}\text { No statistically significant difference } \\
\text { in pain intensity or pain duration }\end{array}$ \\
\hline $\begin{array}{l}\text { Nasri } \\
2016 \mathrm{a} \\
\text { Na,66 } \\
\text { Nasri } \\
2016 \mathrm{~b}\end{array}$ & $\begin{array}{l}4 \\
5\end{array}$ & $\begin{array}{l}\text { High school pupils, } \\
\text { Iran ("Teenagers") }\end{array}$ & $\begin{array}{l}\text { Aerobic group: } \\
\text { - } \quad 45 \text { mins observed "aerobic } \\
\quad \text { exercise", } 3 x / w k \text {; for } 8 \mathrm{wks} \\
\text { Kegel group: } \\
\text { - } 15 \text { mins Kegel exercises; 6s hold, } \\
\quad 3 \mathrm{x} / \text { day }\end{array}$ & $\begin{array}{l}\text { Usual care - "no } \\
\text { exercise", advised } \\
\text { no salty / fatty } \\
\text { foods, no } \\
\text { medications }\end{array}$ & $\begin{array}{l}\text { Pain intensity } \\
\text { via VAS } \\
\text { Pain duration }\end{array}$ & $\begin{array}{l}\text { No statistically significant reduction } \\
\text { in pain intensity / duration between } \\
\text { exercise groups } \\
\text { Statistically significant reduction in } \\
\text { pain intensity / duration compared } \\
\text { to control }\end{array}$ \\
\hline $\begin{array}{l}\text { Ortiz } 2015 \\
50\end{array}$ & $\begin{array}{l}1 \\
9 \\
2\end{array}$ & $\begin{array}{l}\text { Uni students, } \\
\text { Mexico }(18-22 y r s)\end{array}$ & $\begin{array}{l}\text { - Stretches (inc Billig / Kegel), } \\
\text { jogging, relaxation led / monitored } \\
\text { by instructors; 50mins, 3x/wk; for } \\
3 \text { cycles }\end{array}$ & $\begin{array}{l}\text { Kept in } \\
\text { courtyard; } \\
\text { "walking, talking } \\
\text { and standing" }\end{array}$ & $\begin{array}{l}\text { Pain intensity } \\
\text { via VAS }\end{array}$ & $\begin{array}{l}\text { Statistically significant reduction in } \\
\text { pain intensity }\end{array}$ \\
\hline $\begin{array}{l}\text { Patel } 2015 \\
47\end{array}$ & $\begin{array}{l}1 \\
2 \\
0\end{array}$ & $\begin{array}{l}\text { Students, India (17- } \\
25 \mathrm{yrs})\end{array}$ & $\begin{array}{l}\text { - } 6 \text { stretches; 2x/day, 3x/wk for } \\
8 \text { wks }\end{array}$ & Usual care & $\begin{array}{l}\text { Pain intensity } \\
\text { via VAS }\end{array}$ & $\begin{array}{l}\text { Statistically significant reduction in } \\
\text { pain intensity }\end{array}$ \\
\hline
\end{tabular}




\begin{tabular}{|c|c|c|c|c|c|c|}
\hline Study & $\mathbf{n}$ & Participants & Intervention(s) & \begin{tabular}{|c|} 
Comparator(s) \\
\end{tabular} & Outcome(s) & Results \\
\hline $\begin{array}{l}\text { Rakhshaee } \\
201161\end{array}$ & $\begin{array}{l}1 \\
2 \\
0\end{array}$ & $\begin{array}{l}\text { Uni students, Iran } \\
(17-23 \mathrm{yrs})\end{array}$ & $\begin{array}{l}\text { - } 3 \text { yoga poses / breathing } \\
\text { techniques taught by booklet, for } \\
20 \text { mins/day, luteal phase }(14 \mathrm{~d}) \text { of } \\
2 \text { cycles }\end{array}$ & Usual care & $\begin{array}{l}\text { Pain intensity } \\
\text { via } 0-3 \text { scale } \\
\text { Pain duration }\end{array}$ & $\begin{array}{l}\text { Statistically significant reduction in } \\
\text { pain intensity and pain duration }\end{array}$ \\
\hline $\begin{array}{l}\text { Reyhani } \\
201362\end{array}$ & $\begin{array}{l}9 \\
0\end{array}$ & $\begin{array}{l}\text { Nursing/midwifery } \\
\text { students, Iran (Age } \\
\text { range not reported) }\end{array}$ & $\begin{array}{l}\text { - } 30 \text { mins brisk walking (one } \\
\text { training session), } 1^{\text {st }} 3 \mathrm{~d} \text { of } \\
\text { menstruation; for } 3 \text { cycles }\end{array}$ & Usual care & $\begin{array}{l}\text { Pain intensity } \\
\text { via VAS }\end{array}$ & $\begin{array}{l}\text { Statistically significant reduction in } \\
\text { pain intensity }\end{array}$ \\
\hline $\begin{array}{l}\text { Saleh } \\
2016 a \\
57 \\
\text { Saleh } \\
2016 b\end{array}$ & $\begin{array}{l}1 \\
5 \\
0\end{array}$ & $\begin{array}{l}\text { Women from } \\
\text { outpatient clinic, } \\
\text { Egypt (Age range } \\
\text { not reported) }\end{array}$ & $\begin{array}{l}\text { Stretching group: } \\
\text { - } 4 \text { stretches, } 10 \mathrm{mins}, 3 \mathrm{x} / \mathrm{d}, 3 \mathrm{x} / \mathrm{wk} \text {; } \\
\text { for } 8 \mathrm{wks} \\
\text { Core strengthening group: } \\
\text { - } 4 \text { core strengthening exercises, } \\
\quad 20 \mathrm{mins}, 4 \mathrm{x} / \mathrm{wk}\end{array}$ & Usual care & $\begin{array}{l}\text { Pain intensity } \\
\text { via VAS } \\
\text { Pain duration }\end{array}$ & $\begin{array}{l}\text { Statistically significant reduction in } \\
\text { pain intensity / pain duration in } \\
\text { both intervention groups when } \\
\text { compared to control }\end{array}$ \\
\hline $\begin{array}{l}\text { Shahr- } \\
\text { Jerdy } 2012 \\
58\end{array}$ & $\begin{array}{l}1 \\
7 \\
9\end{array}$ & $\begin{array}{l}\text { High school pupils, } \\
\text { Iran (15-17ys) }\end{array}$ & $\begin{array}{l}\text { - } 6 \text { stretches taught initially, } \\
10 \mathrm{mins}, 2 \mathrm{x} / \mathrm{d}, 3 \mathrm{x} / \mathrm{wk} \text {; for } 8 \mathrm{wk}\end{array}$ & $\begin{array}{l}\text { Usual care - } \\
\text { exercises taught } \\
\text { to controls after } \\
\text { study } \\
\end{array}$ & $\begin{array}{l}\text { Pain intensity } \\
\text { via VAS } \\
\text { Pain duration }\end{array}$ & $\begin{array}{l}\text { Statistically significant reduction in } \\
\text { pain intensity and pain duration }\end{array}$ \\
\hline $\begin{array}{l}\text { Siahpour } \\
2013 a \\
\text { Siahpour } \\
\text { 2013b }\end{array}$ & $\begin{array}{l}6 \\
0\end{array}$ & $\begin{array}{l}\text { Uni students, Iran } \\
(20-25 \mathrm{yrs})\end{array}$ & $\begin{array}{l}\text { Aerobic group: } \\
\text { - Aerobic dance for } 60 \text { mins, } \\
\quad 3 \mathrm{x} / \mathrm{wk} \text {; for } 8 \mathrm{wks} \\
\text { Yoga group: } \\
\text { - } \quad 60 \text { mins yoga, } 3 \mathrm{x} / \mathrm{wk} \text {; "trained" }\end{array}$ & Usual care & $\begin{array}{l}\text { Pain intensity } \\
\text { via VAS } \\
\text { Pain duration }\end{array}$ & $\begin{array}{l}\text { Statistically significant reduction in } \\
\text { pain intensity / pain duration } \\
\text { between aerobic and yoga groups } \\
\text { compared to control }\end{array}$ \\
\hline $\begin{array}{l}\text { Sutar } 2016 \\
60\end{array}$ & $\begin{array}{l}1 \\
0 \\
0\end{array}$ & $\begin{array}{l}\text { Medical students, } \\
\text { India (18-22yrs) }\end{array}$ & $\begin{array}{l}\text { Aerobic dance for } 45 \mathrm{mins}, 3 \mathrm{x} / \mathrm{wk} \text {, } \\
\text { for } 8 \mathrm{wks}\end{array}$ & Usual care & $\begin{array}{l}\text { Pain intensity } \\
\text { via VAS }\end{array}$ & $\begin{array}{l}\text { Statistically significant reduction in } \\
\text { pain intensity }\end{array}$ \\
\hline $\begin{array}{l}\text { Yang } \\
2016^{52}\end{array}$ & $\begin{array}{l}1 \\
4 \\
0\end{array}$ & $\begin{array}{l}\text { Nursing students, S } \\
\text { Korea }(20-23 y r s)\end{array}$ & $\begin{array}{l}\text { - } 60 \mathrm{mins} \text { guided yoga, } 1 \mathrm{x} / \mathrm{wk} \\
\text { (poses, sun salutations, relaxation); } \\
\text { for } 12 \mathrm{wks}\end{array}$ & $\begin{array}{l}\text { Usual care - told } \\
\text { not to do yoga }\end{array}$ & $\begin{array}{l}\text { Pain intensity } \\
\text { via VAS } \\
\text { Pain duration }\end{array}$ & $\begin{array}{l}\text { Statistically significant reduction in } \\
\text { pain intensity } \\
\text { No statistically significant reduction } \\
\text { in pain duration }\end{array}$ \\
\hline $\begin{array}{l}\text { Yonglitthip } \\
\text { agon } 2017 \\
59\end{array}$ & $\begin{array}{l}3 \\
4\end{array}$ & $\begin{array}{l}\text { Uni students, } \\
\text { Thailand (18-22yrs) }\end{array}$ & $\begin{array}{l}\text { - } 30 \mathrm{mins} \text { yoga taught by booklet, } \\
2 \mathrm{x} / \mathrm{wk} \text {; for } 12 \mathrm{wks} \\
\text { - Diary / weekly phone calls to } \\
\text { check adherence }\end{array}$ & Usual care & $\begin{array}{l}\text { Pain intensity } \\
\text { via VAS }\end{array}$ & $\begin{array}{l}\text { Statistically significant reduction in } \\
\text { pain intensity }\end{array}$ \\
\hline
\end{tabular}




\section{Figure legends}

Figure 1 - PRISMA flow diagram.

PRISMA flow diagram demonstrating flow of studies through identification process and eligibility screening *See Appendix $C$ for further details

Figure 2 - Risk of Bias Summary

Summary of Risk of Bias of included studies

Figure 3 - Pain intensity meta-analysis

Random effects meta-analysis of pain intensity via $V A S$ in $\mathrm{cm}$

Figure 4 - Pain duration meta-analysis

Random effects meta-analysis of pain duration in hours 
Appendix A - Sample search strategy (Medline / Medline in Process)

$1 \quad \exp$ Dysmenorrhea/ 3600

2 dysmenorrh*.ti,ab. 4950

3 (menstrua* adj2 pain).ti,ab. 720

4 (menstrua* adj2 cramp).ti,ab. 7

5 (period* adj2 pain*).ti,ab. 1372

61 or 2 or 3 or 4 or $5 \quad 7684$

7 exp Exercise/ or exp Exercise Therapy/ 184201

8 exp Physical Exertion/ or exp Physical Fitness/ 79696

9 exp running/ or exp swimming/ or exp walking/81381

10 exp tai ji/ or exp yoga/ 2941

11 exp dancing/ or exp gardening/ or exp sports/ 162811

12 exercis*.ti,ab. 245761

13 "physical activit*”.ti,ab. 82503

14 sport*.ti,ab. 57350

15 stretch*.ti,ab. 62854

16 fitness.ti,ab. 55378

17 jog*.ti,ab. 2026

18 running.ti,ab. 49262

19 swim*.ti,ab. 32718

20 (cycl* adj2 train*).ti,ab. 2065

$21 \quad$ walk*.ti,ab. $\quad 93124$

22 yoga.ti,ab. 3190

23 "tai ji”.ti,ab. 25

24 "tai chi”.ti,ab. 1249

25 pilates.ti,ab. 304

26 “physical training”.ti,ab. 5245

27 "resistance training".ti,ab. 5278

28 (athlete* adj2 train*).ti,ab. 4489

29 “weight training”.ti,ab. 914

30 isometric*.ti,ab. 30361

31 danc*.ti,ab. 5670

327 or 8 or 9 or 10 or 11 or 12 or 13 or 14 or 15 or 16 or 17 or 18 or 19

or 20 or 21 or 22 or 23 or 24 or 25 or 26 or 27 or 28 or 29 or 30 or 31 731463

$33 \quad 6$ and $32 \quad 312$

34 randomized controlled trial.pt. 462560

35 controlled clinical trial.pt. 94063

36 randomized controlled trial.sh. 462560

37 random allocation.sh. 92576

38 double blind method.sh. 147085

39 single-blind method.sh. 24526

4034 or 35 or 36 or 37 or 38 or $39 \quad 645852$ 
$41 \quad$ (animals not human).sh. 6109803

$42 \quad 40$ not $41 \quad 571840$

$43 \quad$ clinical trial.pt. 521341

44 exp clinical trial/ 803438

$45 \quad$ (clin\$ adj25 trial\$).ti,ab. 368228

46 ((singl\$ or doubl\$ or trebl\$ or tripl\$) adj25 (blind\$ or mask\$)).ti,ab. 161643

47 placebos.sh. 34931

48 placebo\$.ti,ab. 192528

49 research design.sh. 96076

5043 or 44 or 45 or 46 or 47 or 48 or 491211208

$51 \quad 50$ not $41 \quad 1110374$

$52 \quad 51$ not $42 \quad 562047$

53 comparative study.sh.1809971

54 exp evaluation studies/ 232296

55 follow up studies.sh. 586124

56 prospective studies.sh. 456986

57 (control\$ or 27 thlete2727ve\$ or volunteer\$).ti,ab. 3751440

5853 or 54 or 55 or 56 or $57 \quad 5717430$

$59 \quad 58$ not $41 \quad 4252943$

$60 \quad 59 \operatorname{not}(42$ or 52$) \quad 3578680$

6142 or 52 or $60 \quad 4712567$

$62 \quad 33$ and $61 \quad 136$ 
Appendix B - Database search returns

\begin{tabular}{|l|l|l|}
\hline Database & Interface & Returns \\
\hline MEDLINE and MEDLINE In Process & Ovid & 136 \\
\hline EMBASE & Ovid & 243 \\
\hline PsycINFO & Ovid & 23 \\
\hline Cochrane Database of Systematic Reviews (CDSR) & Cochrane Library & 40 total* $^{*}$ \\
\cline { 1 - 2 } $\begin{array}{l}\text { Cochrane Central Register of Controlled Trials } \\
\text { (CENTRAL) }\end{array}$ & Cochrane Library & \\
\hline CINAHL & EBSCO & 46 \\
\hline SPORTDiscus & EBSCO & 53 \\
\hline AMED (Allied and Complimentary Medicine Database) & EBSCO & 7 \\
\hline PEDro & NeuRA & 41 \\
\hline Science Citation Index & Web of Science & 231 total* \\
\hline Conference Proceedings and Citation Index & Web of Science & \\
\cline { 1 - 2 } Social Sciences Citation Index & Web of Science & \\
\cline { 1 - 1 } $\begin{array}{l}\text { Conference Proceedings and Citation Index - Social } \\
\text { Sciences and Humanities }\end{array}$ & Web of Science & \multirow{2}{*}{13} \\
\hline Clinicaltrials.gov & $\begin{array}{l}\text { National Institute of } \\
\text { Health }\end{array}$ \\
\hline WHO ICTRP & WHO & 11 \\
\hline OpenGrey & SIGLE & 21 \\
\hline Google & Google & 42 new \\
\hline Citation searching & N/A & 1 new \\
\hline
\end{tabular}

All databases were searched from inception to 24/05/17. SCI/CPCI/SSCI/SS-CPCI and CDSR/CENTRAL were searched simultaneously; there is therefore no individual return numbers for these databases. 
Appendix $\mathrm{C}$ - Excluded studies with reasons for exclusion

A reference list of excluded studies can be obtained from the study authors

\section{Duplicate:}

Azima 2015a- Two arm trial which is also reported as 3 arm trial - see Azima 2015 b below

IRCT2013071013940N1 - Registered trial, results published in Behbahani $2016^{51}$

\section{Unable to get full data:}

Abbaspour 2006 - No inclusion / exclusion criteria, no reply from authors ACTRN12613001195741 - Registered trial and feasibility study, contacted authors who have completed trial and are in process of publishing, however unwilling to share any of data

Arora 2014 - No inclusion / exclusion criteria, no reply from authors Azima $2015 b$ - No inclusion / exclusion criteria in either of papers reporting trial, protocol contains some inclusion / exclusion criteria but does not specify regarding secondary dysmenorrhoea, irregular menstruation or hormonal contraception El Refaye 2007 - Thesis, no online abstract, unable to obtain full text IRCT2016103119024N2 - Registered trial, unable to find published paper, contacted authors and no reply; probably still ongoing as only registered in 2016 Kang 2009 - Thesis, unable to obtain full text Kumar 2013 - No inclusion / exclusion criteria, unable to find contact details for authors

Rezvani 2013 - Unclear whether women using hormonal contraception were excluded, no reply from authors

Rong 2013 - Unclear whether athletes or women using hormonal contraception were excluded, unable to find contact details for authors

Shah 2016 - No inclusion / exclusion criteria, no reply from authors

Yeknami 2015 - No inclusion / exclusion criteria, no reply from authors

\section{Not RCT:}

Anonymous 1945 - Letter

Anonymous 1960 - Letter

Anonymous 1993 - Review

Chien 2013 - Non-randomized controlled trial

Dehghanzadeh - Before and after trial

Golub 1960 - Non-randomized controlled trial

Golub 1963 - Before and after trial

Halder 2012 - Non-randomized controlled trial

Haman1945 - Before and after trial

Harris 1955 - Before and after trial 
Hubbell 1949 - Non-randomized controlled trial

ISRCTN75567759 - Registered trial and published protocol, mixed-methods study with no randomization

Jahromi 2008 - Before and after trial

Locke 1999(1) - Review

Locke 1999(2) - Review

Lundquist 1947 - Non-randomized controlled trial

Mathur 1986 - Non-randomized controlled trial

Athlete population:

Chaudhuri 2013 - Some participants were athletes, also some had irregular periods

(from correspondence with author)

\section{Not primary dysmenorrhoea:}

Heidarianpour 2016 - Menstrual characteristics, dysmenorrhoea considered but did not exclude secondary dysmenorrhoea

Kaur 2014 - No email address found. Unclear whether secondary causes excluded.

Also mentions randomization in abstract but in text participants are "taken at random" Pazoki 2013 - Pre-menstrual symptoms; dysmenorrhoea considered but did not exclude secondary dysmenorrhoea

Pazoki 2016 - Pre-menstrual symptoms; dysmenorrhoea considered but did not exclude secondary dysmenorrhoea

Roozbahani 2015 - Did not exclude secondary dysmenorrhoea

Steege 1993 - Pre-menstrual symptoms; dysmenorrhoea considered but did not exclude secondary dysmenorrhoea

Wilt 1976 - Not specified whether those with secondary cause excluded, unable to obtain information from authors as no contact details

\section{Hormonal contraception not excluded:}

DeWitt 1981 - Asked women about hormonal contraception but did not specify whether these women were excluded

Huang 2007 - No inclusion / exclusion criteria stated, unable to find contact details for authors

Israel 1985 - No inclusion / exclusion criteria stated, unable to find contact details for authors

Mahvash 2012 - No email address found. Unclear whether those on hormonal contraception or with irregular periods were excluded as no inclusion / exclusion criteria were given

Monika 2012 - Hormonal contraception specifically provided to the groups Motesharee 2013 - Hormonal contraception / irregular periods not excluded Nag 2013 - No email address found. Unclear whether athletes included (although have excluded those already practicing yoga), whether those on hormonal contraception or with irregular periods were excluded as no inclusion / exclusion criteria were given 
Not physical activity intervention:

None

Intervention $<8$ weeks:

Gamit 2014 - Four weeks

Kanwal 2016 - One month

Kashef 2014 - Four weeks

Khare 2016 - Three weeks

Mahishale 2013 - First two days of menstruation, only one cycle

Thomas 2010 - Three weeks

Pain not assessed:

Rani 2013 - Hormone profiles assessed as outcome

Vaziri 2015 - Menstrual symptoms assessed as outcome, unable to extract data about pain 
Appendix D - Risk of Bias Assessment

\begin{tabular}{|c|c|c|}
\hline & $\begin{array}{l}\text { Risk of } \\
\text { Bias }\end{array}$ & Justification \\
\hline $\begin{array}{l}\text { Random sequence } \\
\text { generation }\end{array}$ & $\begin{array}{l}\text { Low / } \\
\text { High / } \\
\text { Unclear }\end{array}$ & \\
\hline $\begin{array}{l}\text { Allocation } \\
\text { concealment }\end{array}$ & $\begin{array}{l}\text { Low / } \\
\text { High / } \\
\text { Unclear }\end{array}$ & \\
\hline $\begin{array}{l}\text { Blinding to study } \\
\text { group / study } \\
\text { purpose }\end{array}$ & $\begin{array}{l}\text { Low / } \\
\text { High / } \\
\text { Unclear }\end{array}$ & $\begin{array}{l}\text { Studies were considered at high risk of bias } \\
\text { if they reported that no blinding was done, or } \\
\text { blinding was not reported but the comparator } \\
\text { group received no intervention. }\end{array}$ \\
\hline $\begin{array}{l}\text { Blinding of outcome } \\
\text { assessment }\end{array}$ & $\begin{array}{l}\text { Low / } \\
\text { High / } \\
\text { Unclear }\end{array}$ & \\
\hline $\begin{array}{l}\text { Incomplete outcome } \\
\text { data }\end{array}$ & $\begin{array}{l}\text { Low / } \\
\text { High / } \\
\text { Unclear }\end{array}$ & \\
\hline $\begin{array}{l}\text { Selective outcome } \\
\text { reporting }\end{array}$ & $\begin{array}{l}\text { Low / } \\
\text { High / } \\
\text { Unclear }\end{array}$ & \\
\hline $\begin{array}{l}\text { Other bias (observer } \\
\text { bias, recall bias, } \\
\text { contamination, co- } \\
\text { interventions, } \\
\text { Hawthorne effect) }\end{array}$ & $\begin{array}{l}\text { Low / } \\
\text { High / } \\
\text { Unclear }\end{array}$ & $\begin{array}{l}\text { Studies were considered at high risk of bias } \\
\text { if one of these biases was present. If none of } \\
\text { these biases were adequately described studies } \\
\text { were considered at unclear risk of bias } \\
\text { Interviewer bias - high risk if outcomes } \\
\text { assessed during interview } \\
\text { Recall bias - high risk if outcomes assessed } \\
\text { more than one day after the end of } \\
\text { menstruation } \\
\text { Contamination - high risk if participants were } \\
\text { from schools / colleges / individual courses } \\
\text { unless cluster randomized } \\
\text { Co-interventions - high risk if there was a } \\
\text { co-intervention or physical activity was } \\
\text { performed in a group } \\
\text { Hawthorne effect - high risk if physical } \\
\text { activity was performed in a group or closely } \\
\text { monitored setting }\end{array}$ \\
\hline
\end{tabular}

